\title{
Philosophical and methodological foundations of mutual enrichment by ethnic cultures through the study of social sciences
}

\author{
line 1: Konstantin Kamyshev \\ line 2: College of Vocational \\ Education \\ line 3: Perm State University \\ line 4: Perm, Russia \\ line 5: robespewr@mail.ru
}

\author{
line 1: Vadim Teterin \\ line 2: Department of History, \\ Sociology and Law \\ line 3: FSBEI HE Perm SATU \\ line 4: Perm, Russia \\ line 5: teterinvi@gmail.com
}

\author{
line 1: Alexandr Mehanoshin \\ line 2: Department of \\ Technospheric Security \\ line 3: PNRPU \\ line 4: Perm, Russia \\ line 5: redrex666@mail.ru
}

\author{
line 1: Elisey Chashchin \\ line 2: Department of Philosophy \\ and Law \\ line 3: PNRPU \\ line 4: Perm, Russia \\ line 5: chashin86@mail.ru
}

\begin{abstract}
This graph illustrates the model of the relationship between thinking and values in matters of ethno-cultural identity of students. It must be stipulated that the model is "ideal" and requires practical testing in the conditions of a modern school. (Abstract)
\end{abstract}

Keywords - interethnic interaction, ethno-cultural identity, social and humanitarian education (key words)

\section{INTRODUCTION}

The problem of interethnic interaction in a modern globalizing society not only remains relevant, but even increases. The aggravation of social, including ethnic, conflicts is a consequence of the need to maintain group identity and preserve the borders for certain social groups in relation to the surrounding society.

Globalization conducts to an intensification of migration processes. "The expansion of the scale of these processes led to the formation in the industrial societies of numerous ethnic diasporas, living according to their norms and rules and practically not integrating into the communities of the countries that adopted them, which is a challenge, in particular, of European civilization and its values. The leaders of the largest European states were forced to admit the failure of the policy of multiculturalism: A. Merkel, N. Sarkozy, D. Cameron " [1].

\section{GENERAL PART}

At the same time, the artificiality of generating global values orientated towards ethnic exclusion is a worldwide educational trend. Many world leaders aspire to impose their ethnonational system of coordinates as such installations in order to satisfy the interests of certain groups of elites.
Values, as you know, can not be imposed, they can not be attached or adapted, they must be worked out independently, created, putting with it serious efforts ... The task of the educational process in this case is to give the person the experience of existence in a meaningful world, to form his ability to smyslopologaniyu and smysloporozhdeniyus [2].

As a result of these processes, the main drawback of the new system is the formation of "pseudopolyculturality", the imposition of negative or false identification matrices, sociocultural codes, which inevitably lead to differentiation at a subconscious level. And these features are manifested, both at the collective and at the individual psychological level.

The search for a social regulator of the effectiveness of public life draws our attention to culture as the basis for the organization and self-organization of the pedagogical process. It is in her bosom that a person develops an attitude toward nature, society, himself and the entire global world [3].

Under the influence of special socio-cultural grounds associated with unique historical conditions, there are special mental formations that influence the forms of thinking. Sociocultural thinking becomes more syncretic.

The overwhelming majority of specialists note the specific role of culture as a deterrent, curbing extreme and all forms of intolerance. It is believed that the most effective mechanism for the education of tolerance is, first of all, the study of children of other cultures. Such a mechanism is aimed at the majority of international educational programs and it is assumed that the entire policy of UNESCO is based on it. The distance between the practice of education of tolerance by psychological and pedagogical methods makes us think about creating a fundamentally new mechanism for translating this idea into a 
pedagogical process. As mechanisms for the development of tolerance, researchers propose:

- informing, which means familiarizing the student with the notion of tolerance, criteria and indicators; the study of this phenomenon taking into account the development of human society;

- development of orientations among schoolchildren, including interests, motivations, assessments and norms of behavior, assimilation and application of ethical principles in practice and communication: equality, cooperation, freedom of choice and value self-determination;

- the formation of skills and skills of interpersonal interaction, which is basically familiar with the behavioral side of the process of education of tolerance and independent finding of primary school students ways for spiritual and business communication.

Of particular interest for the subsequent scientific understanding in the mainstream of our research is information of a special nature - one that allows a person to produce his own ethno-cultural identity. A person exists in a certain cultural environment that exerts both direct and indirect influence on him. Mass media, acquaintances and close people from the very childhood can instill in him certain attitudes about his vision of the place of his ethno-cultural environment in the general social space, as well as his attitude to representatives of other ethno-cultural communities.

Each of us identifies himself with this or that social group, thereby trying to order the life, to find the place in the world, to define the role in society, to enter a universum of social stereotypes it what society is ready to perceive the person as the part. In modern Russian society, the state through the education system helps a person to partially solve for himself the problem of self-identification. At the same time process is bidirectional - on the one hand, the person realizes the civil identity, with another the state through citizens begins to define more accurately and clearly the political and sociocultural value. In this connection, the personality of the teacher attaches particular medial importance to the institution of statehood and the subject striving for ethno-cultural self-identification. Often stands behind the qualified teacher the conceiving generation of pupils is reflective. In hands the teacher has to have a tool kit, allowing including to carry out ethno-cultural monitoring at any time to make the flexible and fair decision.

The formation of civic identity as the basic precondition for strengthening Russian statehood and state consolidation of society, socio-cultural modernization of Russia, is the leading direction of modern social and pedagogical activity. Each society educates a citizen for himself, not for the person as such [4].

In our country, social and humanitarian education is the most important factor in the formation of ethno-cultural values in a modern school at each stage of socialization. For most young people, whose thinking develops under the influence of numerous spontaneous conditions associated with the modern external information and communication environment. It is social and humanitarian education that proves to be a structuring beginning, organizing and integrating these disparate sociomatic attitudes into a single integrated conglomerate.

A special role and place in the formation of ethno-cultural identity of modern man plays his ability to global reflexive thinking.

The modern socio-historical period, characterized by multidirectional specialized globalization processes in the political, economic, artistic and other spheres of social life, is characterized by the absence of a rigid identification of the individual in relation to a particular social group. The growth of uncertainty in intra-and inter-group relations at different levels of complexity and localization is accompanied not only by an increase in uncertainty in thinking, but also by the lack of universal ideological foundations. In this case, ideology is understood by us as a set of rational (theoretical understanding, reflection) and irrational (faith, mystical representation) subcultural attitudes. In this sense, the uncertainty of thinking can be called a socio-psychological "compensatory" moment, showing an objective increase in the gap between the technological and socio-cultural aspects of the implementation of society. This circumstance allows us to characterize the transition period between industrial and post-industrial civilization as a "risk society". Modern society is going through various stages of globalization, characterized by the unification, the differentiation of social relations, norms and values.

Going beyond the regulated subject field of certain results of creative activity could have a negative impact on other areas of social consciousness or existence, as violated the overall balance of the complex social system. The result of a largescale crisis that affected all the interrelated spheres of the historical realization of this society was the disintegration of ideological foundations together with the destruction of a single ideological construct for all parts of society. The next step was the search for self-identity by different social groups and the formation of diverse ideologies, reflecting the special view of each group on the social and world order. The speed and intensity with which social changes took place became factors of strengthening of centrifugal processes in thinking. Since the search and Constitution of new worldview, value bases turned out to be a longer process than socio-economic transformations, the formation of integral ideologies began to lag behind the actual division of society into subcultures. The consequences of the formation in the thinking of different communities of ideological vacuum, which began to be filled with reactionary, regressive values, characteristic of previous periods of civilizational development, were complicated by the imposition on the crisis situation in the socialist countries manifestations of the global process of collision of the First and Second global waves. Therefore, ideologies that reflect the specific thinking styles of the social communities that carry them have become many, but most of them are less stable than in the previous periods of history. They are sverresson, variability, inconstancy.

In the language of hazing interaction between the subjects becomes similar to the children's game, reflecting some ideal model of human behavior " inside the game space dominates inherent only to him perfect order ... positive property of the 
game: it establishes the order, it is the order. In this imperfect world, in this turmoil of life, it embodies temporary, limited perfection "[5].

You can find a certain relationship that arises between the number of modern subcultures and thinking styles common in society. If we assume that each social group formed on the common worldview for its members, characterized by a specific style of thinking, and the number of styles formed on a relatively stable combination of types, will correspond to the number of quintessential worldview, characteristic of this public education. The specific style of thinking of each of the subcultures can be designated as the basis for this social group. Not having all the formal characteristics of attributive styles for the thinking of each of the group members, he, along with the mass style of thinking, is able to combine them into a holistic social subject to solve common problems. In this sense, it can be called the predominant style of thinking for a given social environment.

The constant growth of the number of subcultures characteristic of the majority of national or state communities in the modern world is of fruitful importance for the development of society as a whole. This is due to the fact that with the increase in the number of these social communities in the social system as a whole, the number of different types of thinking that are updated in it together with their carriers increases. Diversity, which is a condition for the development of any system, in this case increases. The transition of society to a new nonequilibrium state determined by a consistent increase in the number of growth options opens the way not only to increase the efficiency of the formation of the ideologies of individual subcultures, which is important for countries such as Russia, but thanks to the potential use of various approaches allows us to find more universal polyvariant ways to solve problems of social and global scale. Applying synergetic principles to the known facts of subcultural increase, it is possible to come to the conclusion about the improvement of not only ideological constructs of individual social groups, but also about the possibility of forming new unified rational value worldview standards for a globalizing society. This can become the basis for solving many social contradictions characteristic of the modern stage of the formation of post-industrial civilization. Diversity allows society to obtain a sufficient number of alternatives to find ideological compromises between diverse social actors.

The urgency of resolving these contradictions can be connected with the need to form an adequate socio-historical situation of the worldview. Since the situation of ideological vacuum due to objective reasons related to the ideal selforganization has an effect for a short time, the social worldview is filled with content obtained through the available thinking styles. This circumstance is connected with the phenomenon of substitution of the leading style typical for thinking, which is manifested in the form of a certain kind of competition between different thinking styles. Its purpose is the need to take the leading form in thinking, regulating in a particular worldview the secondary use of other styles in the thinking process. The choice of a particular style as a leader is determined by the current social and historical situation. The effect of this factor is typical for events that occur both during a conditionally taken historical period in General, and for each specific case in particular. For example, in the course of changing the structure of social relations in modern Russia, accompanied by the suppression of the Soviet scientific and philosophical worldview, there was a filling of the complex of thinking components of religious and mystical content, characteristic of the ideological construct of the first civilizational wave. "Only in such transition periods, what we call free will overcomes the pressure of the existing system to restore balance. Thus, fundamental changes are possible, though never predetermined, and this calls for moral responsibility, prompting us to act rationally, with honest intentions and determination to find a better historical system" [6].

In this sense, the ethno-cultural component of selfidentification is one of the key grounds that lie in the space of human determination of his place in the world in the philosophical sense and, to some extent, his social status in the sociological. Global reflexive thinking turns out to be a tool that allows him to achieve this.

The global style can be defined as a universal style, actualized in the thinking of various social groups and reflecting the General trends in the development of society as a whole and, indirectly, the world in General. The basis of such thinking are both "classic": ordinary, mass, theoretical, and newly emerged or radically modified styles of thinking, for example, information, associated with the development and dissemination in society of new information and communication technologies, as well as political, legal, humanitarian.

The principles on which it is based - multi - level reflexivity, globality, understood as universality and mutual responsibility, universal orientation and importance, and information technology of the research-are interconnected with the spread of global reflexive theoretical thinking.

The latter is formed only in a properly organized educational process, involving a special system of interaction between the Teacher and the Student, as well as between the Students themselves.

Various parts of the educational process, compared with the social relevance of a particular historical situation, allow to reveal the mechanisms of a comprehensive understanding necessary for adequate requirements of the society of personal development, not only determined by these historical conditions, but also coming from her, passed the filter of its "common sense" and therefore less dependent on the political side of ideology. In a practical sense, this means the opening of unique worldview accentuations by setting unsolved problems of various branches of educational activity. On the one hand, this allows the subject of education (especially for those who are still in the process of socialization) to choose the branch of their potential specific activity more reasonably. On the other hand, to exclude from this choice as much as possible, as well as from the subsequent implementation of this activity, potentially distorting its results the influence of the political side of ideology in favor of the individually interpreted social and ideological side of it. The educational process in the course of this type of modernization will contain fewer pre-prepared 
empirical data, supporting facts, which will be replaced by basic facts and key methods that require creative thinking and involve a greater number of independent logical conclusions. Carrying out the analysis of the modern historical situation, it is possible to reveal a set of examples of search by scientific and pedagogical branches of society of universal ways of education and education of its members.

At modern Russian school treat disciplines of a social and humanitarian cycle: history, social science, world art culture, social and economic geography, partly literature. They create bases of scientific outlook in the sphere of the interethnic relations and ethno-cultural identity.

In every historical situation there are many people, and all of them have their own intentions, intentions, motions of passions. The general vector of historical development consists of the actions of millions. But the anonymity of the historical process does not cancel his personal character [7].

\section{RESULTS AND DISCUSSION}

Teaching of social and humanitarian disciplines is of paramount importance in achieving general cultural competencies, thanks to their development of participation, they acquire:

1) Ability to understand the driving forces and patterns of the development process of various ethnic communities;

2) The place of a person in the process of development of ethnic communities, in the political, social, cultural organization of society;

3) The role of Russia and the peoples inhabiting it in the history of mankind and at the present stage;

4) The causal relationship between the development of various ethnic communities in Russia from the point of view of building a global world;

5) The notion of the need to observe universal, humane, moral laws and norms in the sphere of interethnic interaction;

6) Ability to show personal qualities - civil, moral, intellectual, general culture, and influence on them of the ethnic factor;

7) The desire of ethnic communities to live in harmony with the world around them.

It is believed that in the structure of the worldview position three interrelated components will be singled out: axiological, cognitive, behavioral. Fundamentals of human representations of the world around, views and beliefs constitute worldview knowledge. However, for the formation of a relationship, it is necessary that the information received is felt, experienced by a person, and only after that it is appropriated by the person [8]. However, as in any socially oriented research, it should be taken into account that, the degree of awareness of the need to consider methodological problems varies widely [9].

On the basis of the theoretical and methodological foundations we examined, we carried out a theoretical analysis of the current situation among students. The result of the analysis is a single scale along the line of separation: cultural openness, self-elevation - self-transcendence. On its basis, extremes are identified, based on the principle of "ethnocentrism - ethnonihilism". According to the task in hand, we can form a specific scale-meter for analysis or self-analysis by a person of his ethno-cultural values in this sense, on the one hand, we get value orientations whose extreme manifestations are: ethnocentrism - hypertrophied ethnic identity, the recognition of the ethnos main (in some cases the only) form of human coexistence and ethnonihilism - rejection of ethnic identity, ignoring (in extreme form, complete denial) of the ethnos as forms of social mind, on the other - the criterion of evaluation itself.

Systemic cluster analysis of ethnic consciousness allows us to distinguish the following coordinate systems: first, the criterion, the reflexivity allows us to determine the ability of the researcher to self-analysis and to substantiate his clear position on the issue of ethno-cultural interaction; secondly, the value criterion determining the attitude of the researcher to his ethnic consciousness and self-consciousness as an individual and a member of certain social groups; thirdly, a behavioral criterion that determines the real interethnic interaction of different actors.

Teachers of higher educational institutions, teachers of secondary schools, teachers of kindergartens have the most important task - to develop the ability of the young generation to exercise their choice on the basis of the spiritual and moral values of their people and peoples of the world ... [10]. Thinking of the school student can be empirical, analytical, planning and reflexing. E.M. Kalashnikova claims that ability to social identification only the socialized person conceiving has is reflective [11]. Since the formation of one or another level of development of thinking is a prerequisite for the future development of the next level of development, therefore, there is the possibility:

1) Adoption of these levels as a criterion for evaluating the property under study;

2) Adopting the next following the established level as a direction for the subsequent development of thinking and determining the closest zone of development of the student's thinking;

3) Drawing up an adequate set of exercises on one or a number of subjects, the implementation of which should lead to the achievement of the student's appropriate level of development of thinking [12].

The very possibility of such an approach was provided by the author of the theory, Sh. Schwartz: "The circular arrangement of values is rather a continuum of related motifs, more like a color spectrum than a set of individual motivations. It can be divided into broader or more narrow value constructs ... "[13].

\section{PRACTICAL RESUltS}

To conduct a mathematical analysis of the results obtained, they were led to a unified system for which all measurements were reduced to a single type for which to take a proportional 
scale type where the maximum and maximum values were taken to fit the population.

Based on the refined theory of the basic individual values of Sh. Schwartz (A Refined Theory of Basic Personal Values).

Elements of axiological scaling (in the coordinate system):

\section{1) Ethnocentrism (10-9)}

2) The axiological "ethno-chauvinism" (8-7)

3) Negative ethnoidentity (6-5)

4) "Naive" ethnocentrism (4-3)

5) Critical ethnocentrism (2-1)

6) Positive value ethnic identity (0)

7) Ethnoinfantilism (-1- -2)

8) Ethnoscepticism (-4 - -3)

9) Ethnophobia (-6 - -5)

10) Ethnic Collaboration (-8 - -7)

11) Ethnonihilism (-10 - -9)

A system is built in which: "... at one extreme pole - inclined to traditionalism and ambition, which speaks of their propensity to ethnocentrism; the positions of their antipodes - a tendency to self-transcendence and openness in the field of intercultural communication, which is evidence in favor of their ethnonihilism. " These ratios are presented in Table 1.

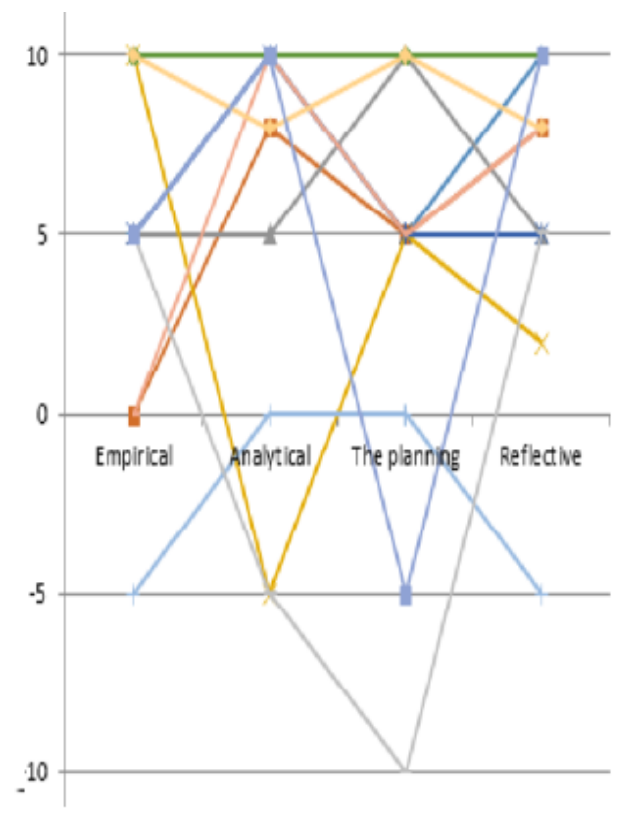

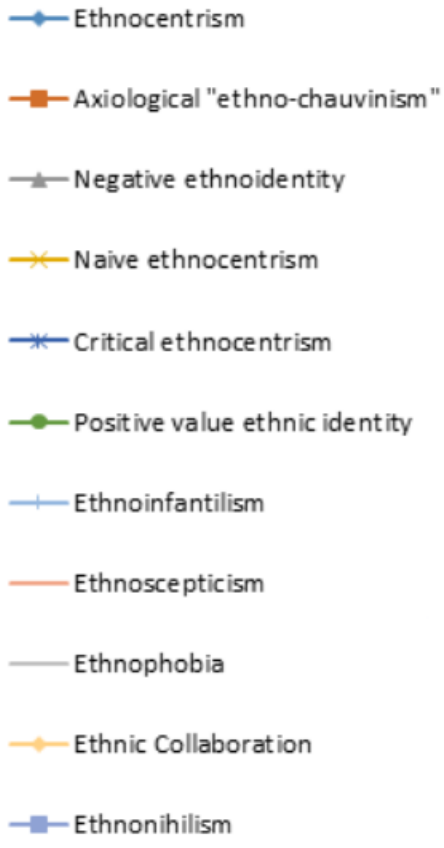

\section{REFERENCES}

This graph illustrates the model of the relationship between thinking and values in matters of ethno-cultural identity of students.

At the initial stage of modeling for the initial hypothesis it should be assumed that the general population does not obey the law of normal distribution. Primary assessment allows to assume presence of two and more groups investigated.

Theoretical analysis suggests that the grouping and generalization of objects can be made at least two, but rather three, four features.

Of these, only the level of development of thinking can be estimated quantitatively, the remaining indicators can be assessed either qualitatively or expertly.

For the processing of results, the method of automatic clustering is promising. Automatic clustering of objects should be understood as the process of classifying groups of objects, proceeding only from analysis and revealing the internal structure of the group without the presence of a priori information about it. Classification of objects using clustering algorithms leads to the partitioning of the set of objects of research into homogeneous groups, or clusters, by means of an automatic analysis of proximity measures between them.

Clustering of objects is based on the cluster hypothesis: closely related objects tend to be relevant to the same queries, that is, objects relevant to the query are detachable from those not relevant to this query.

Systemic cluster analysis of ethnic consciousness allows us to distinguish the following coordinate systems: first, the criterion, the reflexivity allows us to determine the ability of the researcher to self-analysis and to substantiate his clear position on the issue of ethno-cultural interaction; secondly, the value criterion determining the attitude of the researcher to his 
ethnic consciousness and self-consciousness as an individual and a member of certain social groups; thirdly, a behavioral criterion that determines the real interethnic interaction of different actors.

To objectively determine the number of clusters from the results of studies, it is proposed to construct a weighted connected non-oriented graph for which to find a spanning tree having a minimum sum of weight coefficients. Further from mathematical considerations, the number of isolated groups is equal to the number of anomalously long branches plus one.

The received coefficient will allow to make breaks according to the Algorithm of the maximization of expectation (AME). A particular case of AME is the k-average algorithm for which there are a number of reliable software tools.

To check the results of clustering, it is suggested to calculate the mathematical expectation and variance for each of the groups at a high level of reliability of the study. The expectation of groups should be extremely distinguishable and the variance for differing within the same order.

The application of this evaluation method must prove that this "ideal model" corresponds to the real results of practical testing in the conditions of the modern school.

[1] IK. Kiryanov, LA. Obukhov. A new study on the history of ethnically dispersed groups of peoples of the Middle Urals. Bulletin of Perm University. Series: History and Political Science. Issue 3 (17). Pp. 154156 .

[2] EN. Korobkova Cultural-oriented educational process in the context of modern school modernization strategy. Problems of the modern pedagogical education. Anija Ser .: Pedagogy and Psychology Collection of articles:. -. Yalta, 2016 - No. 53 - Part 6. pp. 226-227.
[3] LI. Lurie. Scientific-pedagogical activity as social and cultural innovation. Siberian Pedagogical Journal, 2014. No. 5. Pp. 167-173.

[4] MA Zhigunova. The role of the historical and cultural heritage of the Cossacks of the Ural-Siberian region in the education of modern Russian youth. Cossacks of Siberia from Ermak to the present day: history, language, culture Tyumen, 2017 p.45.

[5] J. Hazing. Homo Ludens. Articles on the history of culture. - M.: Progress-Tradition, 1997. p. 39

[6] I. Wallerstein. The end of the familiar world. Sociology of the XXI century. - M.: Logos, 2003 p. 8

[7] AP Pigunova, ID Vageneytner. Personality in society and history. Humanitarian sciences in the 21st century, M. 2013, pp. 152-155.

[8] R. M.A. Kolesnikov, N.I. Ippolitova, Worldview Preparation as a Component of the Personal Formation of Future Educators. M.A. Kolesnikov, N.I. Ippolitova, Worldview Preparation as a Component of the Personal Formation of Future Educators. pp. 122-129.

[9] IA Sykalov. Degree and character of presentation of metodogical problems in educational sociological literature. Bulletin of Perm University. Series: Philosophy, Psychology, Sociology., Issue 1 (1). 2010. P.121.

[10] GA Ermakova, NI Yakimova, OV Sorokina, MP Savirova. Formation of spiritual needs in a multicultural environment (the formation of the soul as a strategic project). Problems of modern pedagogical education., Ser $\therefore$ Pedagogy and Psychology .-- Collection of articles: - Yalta, 2016. issue 51 - P. 6. P. 123

[11] Sh. Shvarts, TP Butenko DS Sedov A.S. A refined theory of basic individual values: application in Russia. Lipatova Psychology t.№9 №2 2012 HSE.

[12] E.M Kalashnikova. Methodological value of the concept "selfidentification" of social researches//Bulletin of the Vyatka State University Magazine. Philosophy, sociology, cultural science No. 1, 2014. P. 6.

[13] V.I. Zagvyazinsky, FR. Atakhanov. Metodologiya and methods of a psychology and pedagogical research: Studies. a grant for student. - M.: Publishing center "Akademiya", 2003. 